\title{
Symbiosis-Induced Cascade Regulation of the Mesorhizobium loti R7A VirB/D4 Type IV Secretion System
}

\author{
Andree M. Hubber, John T. Sullivan, and Clive W. Ronson \\ Department of Microbiology and Immunology, University of Otago, PO Box 56, Dunedin, New Zealand
}

Submitted 7 August 2006. Accepted 28 September 2006.

\begin{abstract}
The Mesorhizobium loti R7A symbiosis island contains genes encoding a VirB/D4 type IV secretion system (T4SS) similar to that of Agrobacterium tumefaciens. This system has host-dependent effects on symbiosis that probably are due to translocation of two effector proteins, Msi059 and Msi061, into host cells. Here we report that, as in A. tumefaciens, the $M$. loti vir genes are transcriptionally regulated by a VirA/VirG two-component regulatory system. A virGN54D mutant gene of $M$. loti caused constitutive expression of lacZ reporter gene fusions to virB1, virD4, msi059, and $m s i 061$. Expression of these gene fusions also was activated by a NodD gene product from Rhizobium leguminosarum in the presence of the inducer naringenin, as was a virA::lacZ fusion. This activation was dependent on a nod box present 851 bp upstream of virA, and a mutant with the nod box deleted formed effective nodules on Leucaena leucocephala, the same symbiotic phenotype as other $M$. loti vir mutants. In contrast, the wild-type strain formed small, empty nodules whereas a nodD1 mutant was completely Nod'$^{-}$. These results indicate that the $M$. loti vir genes are induced in a symbiosis-specific manner that involves a two-tiered regulatory cascade, and that the vir effectors act after Nod factor during infection thread formation.
\end{abstract}

Rhizobia are $\alpha$ - and $\beta$-proteobacteria that form nitrogenfixing root nodules on leguminous plants. To establish a successful symbiotic association, molecular signals are exchanged between the two partners (Perret et al. 2000; Spaink 2000; van Rhijn and Vanderleyden 1995). In the early stages of this communication, legumes secrete species-specific flavonoids into the rhizosphere that are recognized in a Rhizobium sp.-specific manner by NodD proteins. Members of the LysR family, NodD proteins bind to nod boxes in the promoter regions of inducible nod genes (Fisher and Long 1993; Long 1996; Peck et al. 2006; Rostas et al. 1986). Rhizobial Nod proteins create Rhizobium sp.-specific lipochito-oligosaccharide signaling molecules known as Nod factors (Long 1996; Spaink 2000). Nod factors probably are recognized by plant receptors, and thereby activate signaling pathways required for nodule development and rhizobial invasion (Geurts et al. 2005; Limpens et al. 2003; Madsen et al. 2003; Radutoiu et al. 2003).

Depending on the individual Rhizobium sp.-legume pairing, rhizobial surface polysaccharides also influence infection thread formation and nodule development (Becker et al. 2005; Fraysse et al. 2003; Gage 2004; Noel and Duelli 2000; Price 1999;

Corresponding author: Clive Ronson; Telephone: (+64) 3479 7701; Fax: (+64) 3479 8540; E-mail: Clive.Ronson@stonebow.otago.ac.nz
Spaink 2000). In addition, type III secretion systems (T3SS) in Rhizobium sp. strain NGR234, Sinorhizobium fredii, and Bradyrhizobium japonicum have been shown to transport nodulation outer proteins (Nops) to the extracellular milieu. Mutations that perturb the T3SS machinery cause symbiotic phenotypes on some hosts but are phenotypically silent on other hosts (Ausmees et al. 2004; Krause et al. 2002; Krishnan et al. 2003; Lorio et al. 2004; Marie et al. 2003; Viprey et al. 1998). Mutations within genes that code for individual Nops cause different symbiotic phenotypes depending on the host studied (Ausmees et al. 2004). The NopL and NopP effectors of Rhizobium NGR234 serve as substrates for plant protein kinases (Bartsev et al. 2003; Skorpil et al. 2005), and expression of NopL in plant cells suppresses a full plant defense response (Bartsev et al. 2004).

The Mesorhizobium loti R7A symbiosis island contains genes (virB1 to B11 and virD4) that encode a type IV secretion system (T4SS) with a high degree of similarity to the Agrobacterium tumefaciens vir T4SS that transfers T-DNA and several proteins to plants (Christie et al. 2005; Sullivan et al. 2002). Mutations in the $M$. loti vir genes have host-dependent effects, causing delayed nodulation on Lotus corniculatus and allowing effective nodulation on Leucaena leucocephala (Hubber et al. 2004). Additionally, mutants in a gene msi059 that codes for a putative cysteine protease effector protein transported by the system show symbiotic effects similar to that of the vir gene mutants (Hubber et al. 2004). The host-dependent symbiotic phenotypes of the mutants may reflect differences in the hosts' reactions to secreted effector proteins. In L. leucocephala, the effector proteins may induce plant defense responses, analogous to the avirulence proteins of plant pathogens, resulting in abortion of infections; whereas, in Lotus corniculatus, they may facilitate infection, perhaps by suppressing plant defense reactions (Hubber et al. 2004; Marie et al. 2001).

Homologues of the A. tumefaciens regulatory virA and virG genes also are present on the $M$. loti R7A symbiosis island (Fig. 1) and strains with mutations in these genes form effective nodules on Leucaena leucocephala (Hubber et al. 2004). In A. tumefaciens, VirA and VirG constitute a two-component regulatory system that activates the other vir genes in response to plant signals (Leroux et al. 1987; Winans et al. 1986). Compounds released from plant wound sites induce the inner membrane-bound VirA dimer to transphosphorylate itself at His474 (Huang et al. 1990; Jin et al. 1990a and b), and to phosphorylate the cytoplasmic response regulator VirG at Asp-52 (Jin et al. 1990b). VirG then binds at conserved hexameric DNA sequences termed vir boxes in vir operon promoter regions to induce their transcription (Das et al. 1986; Gao et al. 2006; Jin et al. 1990c; Pazour and Das 1990; Powell et al. 
1989). The dependence of VirG on VirA for activation can be alleviated by a mutation that gives the variant protein VirGN54D; this protein does not require VirA for phosphorylation (Gao et al. 2006) and activates the other vir operons constitutively (Han et al. 1992; Jin et al. 1993; Pazour et al. 1992; Scheeren-Groot et al. 1994).

Previously, we reported the presence of two vir-box consensus nucleotide repeats within the $M$. loti R7A symbiosis island sequence, one in the promoter region of the msi061 gene and the other in the intergenic region between the divergently transcribed virB1 and virG genes (Hubber et al. 2004) (Fig. 1). In addition, a putative nod box was found 851 bp upstream of virA (Fig. 1) and no genes were annotated in the intervening region (Hubber et al. 2004; Sullivan et al. 2002), suggesting a link between vir and nod gene expression. Here, we report that the M. loti vir genes are subject to cascade regulation, first through NodD via the nod box upstream of virA and then through VirA/VirG.

\section{RESULTS}

The structural vir operons are regulated by VirG.

$M$. loti VirG and the VirG homologues from several A. tumefaciens plasmids share over $72 \%$ identity over their entire lengths. The $M$. lot $i$ VirG protein contains the asparagine residue at position 54 that, when mutated to an aspartic acid residue, results in VirG variants that constitutively activate vir gene expression (Han et al. 1992; Jin et al. 1993; Pazour et al. 1992; Scheeren-Groot et al. 1994). Therefore, an analogous M. loti virGN54D mutant was constructed by site-directed mutagenesis as described in Materials and Methods, and the gene and its promoter region were cloned into the broad-host-range vector pFAJ1700 to produce pAH4.

The effect of pAH4 on M. loti vir gene expression was assayed by introducing the plasmid into strains containing vir::lacZ reporter gene fusions. These strains were constructed by homologous recombination-mediated insertion of the suicide vector pFUS2, such that either an insertion duplication mutant (IDM) with a transcriptional fusion between the $5^{\prime}$ end of the mutated gene and lacZ was created or, in the case of strain AH71 (msi061-CMD::lacZ), a cis-merodiploid (CMD) strain was created that retained an intact copy of msi061 and its promoter downstream of the integrated plasmid and msi061::lacZ fusion. Results of $\beta$-galactosidase assays showed that the presence of pAH4 caused increased expression of the virB $1::$ lacZ, virD4::lacZ, msi059::lacZ, msi061::lacZ, and msi061$C M D:: l a c Z$ fusions (Table 1). The msi061-CMD::lacZ fusion also was induced by pAH4 in $\triangle v \operatorname{ir} A$ and $\Delta v \operatorname{vir} G$ strains, indicating that induction was independent of the wild-type regulatory genes as expected. In contrast, the virA::lacZ and virG::lacZ fusions showed similar levels of expression in the presence or absence of pAH4 (Table 1). These results showed that VirG regulates the expression of the structural vir operons virB1virB11 and msi061-virD4-msi059, but not of itself or virA.

\section{M. loti vir gene induction is under symbiotic control.}

The presence of a putative nod box in the region upstream of virA suggested that nod gene inducers might activate vir gene expression. Plant molecules capable of activating the $M$. loti NodD protein at physiological concentrations have not been found. However, the NodD protein of R. leguminosarum bv. viciae, produced from the nodD gene cloned in pMP2112, activates $M$. loti nod genes in the presence of the flavonoid naringenin (Lopez-Lara et al. 1995; Niwa et al. 2001). The plasmid pMP2112 was introduced into various $M$. loti lacZ fusion strains, which then were assayed for $\beta$-galactosidase induction. In the presence of both pMP2112 and naringenin, there was significantly greater expression of the positive controls nodB::lacZ and nolO::lacZ, and also of virA::lacZ, virB1::lacZ, virD4:: lacZ, and msi061::lacZ fusions (Table 2). This increase was dependent on pMP2112 and inducer, because expression of the fusions was not enhanced by pMP2112 (Table 2) or naringenin
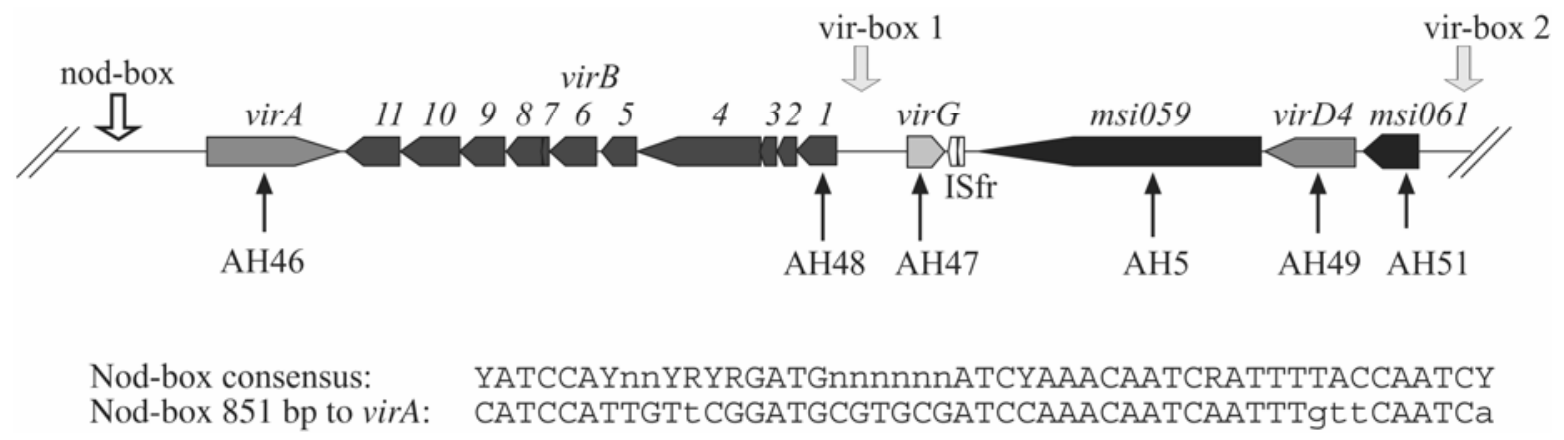

Fig. 1. Genetic organization of the Mesorhizobium loti R7A vir gene cluster. The locations of various vir genes are indicated by arrows. Also shown are the locations of a nod box and two putative vir boxes (Hubber et al. 2004). The nod box consensus was from van Rhijn and Vanderleyden (1995). Y = pyrimidine $(\mathrm{C}, \mathrm{T}) ; \mathrm{R}=$ purine $(\mathrm{G}, \mathrm{A}) ; \mathrm{N}=$ any base.

Table 1. Effect of pAH4 (virG(N54D)) on expression of vir::lacZ fusions in Mesorhizobium loti ${ }^{\text {a }}$

\begin{tabular}{|c|c|c|c|}
\hline Fusion strain & - pAH4 & + pAH4 & Fold induction \\
\hline AH46 (R7A virA::lacZ) & $36.7 \pm 2.9(24)$ & $31.7 \pm 2.7(2)$ & 0.9 \\
\hline AH47 (R7A virG::lacZ) & $24.2 \pm 3.1(3)$ & $24.3 \pm 3.2(3)$ & 1.0 \\
\hline AH48 (R7A virB1::lacZ) & $14.2 \pm 1(5)$ & $22 \pm 0.7(5)$ & $1.6 *$ \\
\hline AH49 (R7A virD4::lacZ) & $19.3 \pm 1.6(3)$ & $488.1 \pm 40.9(3)$ & $25.6^{*}$ \\
\hline AH50 (R7A msi059::lacZ) & $33.6 \pm 2.0(4)$ & $208.8 \pm 27.8(4)$ & $6.8 *$ \\
\hline AH51 (R7A msi061::lacZ) & $77.4 \pm 8.5(5)$ & $1286.1 \pm 83.3(5)$ & $15.5^{*}$ \\
\hline AH71 (R7A msi061-CMD::lacZ) & $84.4 \pm 12(3)$ & $851.7 \pm 59.0(4)$ & $10.1^{*}$ \\
\hline AH90 (R7A $\Delta v i r A ~ m s i 061-C M D:: l a c Z)$ & $10.1 \pm 0.2(5)$ & $55.8 \pm 3.2(5)$ & $5.5^{*}$ \\
\hline AH91 (R7A $\Delta v i r G$ msi061-CMD::lacZ) & $19.7 \pm 0.1(3)$ & $259.22 \pm 24.3(5)$ & $14.6^{*}$ \\
\hline
\end{tabular}

${ }^{\mathrm{a}}$ Cultures used for assays were grown in $M$. loti G/RDM broth, $\mathrm{pH}$ 6.0, until they reached mid exponential phase (optical density at $600 \mathrm{~nm}=$ approximately $0.5)$. The number of independent assays for each strain is shown in brackets. Asterisks indicate significant induction of the fusion in response to pAH4 $(P<$ 0.05 as determined by $t$ test). 
(data not shown) alone. Addition of pMP2112 and naringenin did not affect the expression of virG::lacZ or the negative control nifA1::lacZ. These results are consistent with NodD inducing expression of the structural vir operons through activating expression of virA.

\section{The nod box upstream of virA is required} for vir gene activation.

To investigate the role of the nod box located 851 bp upstream of virA in the transcriptional control of virA, a mutant in which the nod box was deleted was constructed using a marker replacement strategy. To confirm the role of the virA nod box in NodD-mediated vir gene activation, the gene fusions virA::lacZ, virG::lacZ, virB1::lacZ, and virD4::lacZ were each integrated into the $\Delta$ nod-box strain AH55 to create strains AH63, AH64, AH65, and AH66, respectively. No increases in vir gene expression of these strains in the presence of pMP2112 and naringenin occurred compared with uninduced cultures (Table 2).

The $\Delta$ nod-box:: $\Omega$ kan strain AH55 also was tested for its nodulation phenotype on $L$. leucocephala plants, together with wild-type and other vir mutant strains. The vir gene mutants, including AH55, formed large, pink nodules (2 to $5 \mathrm{~mm}$ in length) with an oblong and often multilobed structure, whereas strains R7A and NZP2213 formed small, white, round nodules 0.5 to $1 \mathrm{~mm}$ in diameter (Fig. 2). Taken together, these results confirm that the nod box upstream of the virA is required for the symbiotic expression of the virA, virB, and msi061 operons.

\section{The nodD1 gene of $M$. loti most likely mediates} nod and vir gene activation.

To examine the roles of the symbiosis island nodD1 versus nodD2 gene products in vir gene regulation, mutants were obtained with EZTn-GN insertions in either nodD gene. The nodu- lation phenotypes of these mutants were analyzed on L. leucocephala. Like R7A, the nodD2 mutant induced small, white, nodule-like structures, whereas the nodDl mutant failed to form any such structures (Fig. 2).

\section{DISCUSSION}

We have shown that the expression of the M. loti T4SS machinery is tightly controlled and subject to cascade regulation, requiring first the perception of plant-derived signals through NodD1 and subsequently activation by the VirA/VirG twocomponent regulatory system. Like the A. tumefaciens T4SS, regulation of the $M$. loti vir system by VirA/VirG probably occurs via VirG binding to vir boxes present upstream of the virB1 and msi061 genes. Also inherent in the regulation of both systems is the perception of environmental signals. However, unlike A. tumefaciens virA, the $M$. loti virA gene is under transcriptional regulation, its expression being mediated through the nod box located $851 \mathrm{bp}$ upstream of the start codon of the gene. This key feature of the M. loti vir gene regulatory cascade links the timing of vir gene expression to the early stages of nodule invasion.

The involvement of the nod box in vir gene expression was demonstrated by the findings that the $\Delta$ nod box mutant strain AH55 showed the same distinctive phenotype as vir mutants on L. leucocephala, and that NodD-mediated induction of vir gene expression was abolished in the mutant. The virA nod box is one of only two nod boxes on the symbiosis island of M. loti R7A not associated with genes involved in Nod factor synthesis (Sullivan et al. 2002). The distances from the start codons of the nod operons to the nod box consensus varies greatly, from 67 to $658 \mathrm{bp}$; however, at $851 \mathrm{bp}$ upstream of the start codon, the virA nod box is unusually far upstream of the gene it controls. The transcriptional start sites have not been determined for the $M$.

Table 2. Expression of nod::lacZ and vir::lacZ fusions in Mesorhizobium loti R7A containing nodD from Rhizobium leguminosarum (pMP2112) ${ }^{\mathrm{a}}$

\begin{tabular}{|c|c|c|c|}
\hline Fusion strain & + pMP2112 - Naringenin & + pMP2112 + Naringenin & Fold induction \\
\hline AH46 (R7A virA::lacZ) & $27.4 \pm 1.4(5)$ & $55.6 \pm 4.3(5)$ & $2.0 *$ \\
\hline AH47 (R7A virG::lacZ) & $39.39 \pm 3.6(3)$ & $44.27 \pm 7.7(3)$ & 1.1 \\
\hline AH48 (R7A virB1::lacZ) & $10.3 \pm 1.8(5)$ & $64.3 \pm 10.1(7)$ & $6.2 *$ \\
\hline AH49 (R7A virD4::lacZ) & $21.5 \pm 1.5$ & $76 \pm 9.1(4)$ & $3.5^{*}$ \\
\hline AH50 (R7A msi059::lacZ) & $22.6 \pm 2.2(6)$ & $87.9 \pm 21.3(3)$ & $3.9^{*}$ \\
\hline AH51 (R7A msi061::lacZ) & $44.4 \pm 2.7$ (4) & $90.3 \pm 12.4(4)$ & $2.0 *$ \\
\hline AH52 (R7A nifA $1:$ lacZ) & $2.54 \pm 0.3(3)$ & $1.95 \pm 0.6(3)$ & 0.8 \\
\hline AH61 (R7A nolO::lacZ) & $9.99 \pm 0.3(3)$ & $109.33 \pm 17.6(3)$ & $10.9 *$ \\
\hline AH62 (R7A nodB::lacZ) & $23.05 \pm 3.4(3)$ & $256.40 \pm 56.8(3)$ & $11.1 *$ \\
\hline 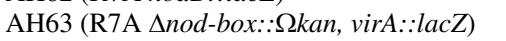 & $10.94 \pm 1.5(3)$ & $9.68 \pm 0.7(3)$ & 0.9 \\
\hline 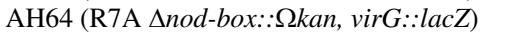 & $30.6 \pm 0.3(3)$ & $30.4 \pm 0.4(3)$ & 1.0 \\
\hline AH65 (R7A $\Delta$ nod-box:: $\Omega$ kan, virB1::lacZ) & $8.47 \pm 1.5(3)$ & $8.77 \pm 1.5(3)$ & 1.0 \\
\hline AH66 (R7A $\Delta$ nod-box:: $\Omega$ kan, virD4::lacZ) & $12.11 \pm 0.8(3)$ & $14.9 \pm 1.6(3)$ & 1.2 \\
\hline
\end{tabular}

${ }^{\mathrm{a}}$ Cultures used for assays were grown in $M$. loti G/RDM broth, $\mathrm{pH}$ 6.0, until they reached stationary phase (optical density at $600 \mathrm{~nm}>1.0$ ). In each assay, samples were assessed in duplicate. The number of independent assays for each strain is shown in brackets. Asterisks indicate significant induction of the fusion in response to naringenin $(P<0.05$ as determined by $t$ test).

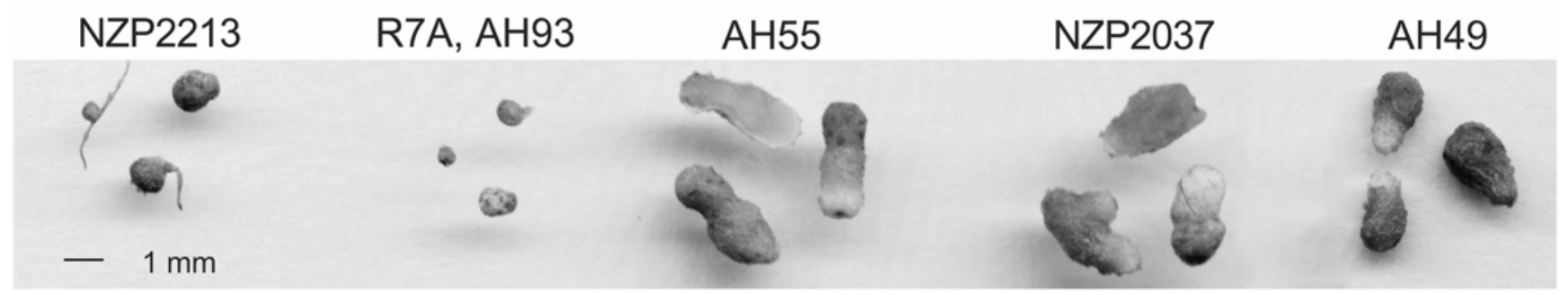

Fig. 2. Photographs of 12-week-old Leucaena leucocephala nodules from plants inoculated with strains of Mesorhizobium loti. Plants inoculated with NZP2213, R7A, and AH93 (nodD2::EZTn-GN) had small (0.5 to $1 \mathrm{~mm}$ ), round nodules, whereas plants inoculated with NZP2037, AH49 (virD4::lacZ), and AH55 ( $\Delta$ nod-box:: $\Omega$ kan $)$ had large ( 2 to $5 \mathrm{~mm}$ ), pink, elongated nodules, often with a multilobate structure. Plants inoculated with AH92 (nodD1::EzTn5) were devoid of nodule-like structures. 
loti nod genes or virA; however, for several characterized nod genes, the transcriptional start sites are 23 to 35 bp downstream of the conserved 26-bp section of the nod-box consensus (Schlaman et al. 1998). If this is the case for virA, then its $5^{\prime}$ transcribed but untranslated region is approximately $800 \mathrm{bp}$. The strong similarity between the $A$. tumefaciens and $M$. loti vir systems indicate that they share a relatively recent common ancestor; therefore, the M. loti nod box upstream of virA probably was acquired by a recent recombinational event. Hence, the spacing may be suboptimal and it could be continuing to evolve. Alternatively, the region may be involved in fine-tuning the level of virA expression; it also is possible that this region contains a pseudogene. Several nod genes in other rhizobial species have long untranslated leader sequences but the regions do not show sequence conservation and no function has been assigned to them (Schalaman et al. 1998).

Previously, we have shown that T3SS mutants of $M$. loti MAFF303099 exhibit a similar phenotype to the strain R7A VirB/D4 T4SS mutants on L. leucocephala, suggesting that T3SS and T4SS systems play interchangeable roles in different strains of M. loti (Hubber et al. 2004). The NodD-mediated activation of the $M$. loti T4SS observed in this study is similar to that reported for T3SS from S. fredii, B. japonicum, and Rhizobium sp. strain NGR234. In these systems, transcription of a regulatory gene ttsI is activated by NodD in a flavonoid-dependent manner, and TtsI, in turn, activates operons required for T3SS synthesis and function (Krause et al. 2002; Marie et al. 2004; Viprey et al. 1998). Although TtsI is a member of the twocomponent response regulator family, it is thought to be a constitutive activator because a cognate sensor histidine kinase has not been identified and it contains a glutamate residue instead of the conserved aspartate residue shown to be the primary phosphoacceptor in OmpR from Escherichia coli and NtrC of Salmonella typhimurium. The analogous aspartate to glutamate substitution in OmpR or NtrC leads to their constitutive activation (Delgado et al. 1993; Klose et al. 1993; Lan and Igo 1998; Marie et al. 2004). It is proposed that the cascade regulation of the T3SS system in these rhizobia allows for temporal expression such that the T3SS is formed after production of Nod factors, reflecting the likely function of the T3SS in suppressing plant defense responses during infection thread formation and development (Kobayashi et al. 2004; Marie et al. 2004).

The A. tumefaciens VirA protein activates VirG by phosphorylation in response to a combination of three plantreleased chemical signals, namely phenolic compounds such as acetosyringone, particular monosaccharides involved in plant cell wall synthesis, and acidic $\mathrm{pH}$ (Brencic and Winans 2005; Zhu et al. 2000). These signals reflect the plant wound response and new cell-wall synthesis at the site of the wound. The NodD-dependent activation of the various vir::lacZ fusions was highly reproducible (Table 2), indicating that $M$. loti VirA must be at least partially active as a VirG protein kinase under our in vitro assay conditions. Nevertheless, it seems likely that the $M$. lot $i$ VirA also senses plant-derived signals when activating VirG, a suggestion supported by our observation that VirGN54D gave much higher levels of $\beta$-galactosidase activity from msi059::lacZ, virD4::lacZ, and msi061::lacZ fusions than did the NodD protein from $R$. leguminosarum in the presence of naringenin (Tables 1 and 2). However, the virB1::lacZ fusion showed the opposite pattern of expression (Tables 1 and 2 ), for reasons that are currently not clear. It may be that high expression of the virB::lacZ mutant was deleterious to the cell because a truncated VirB1 peptide would be produced. VirB1 is a lytic transglycosylase that normally is translocated across the inner membrane (Christie et al. 2005) and, because the truncated peptide contains a signal sequence, it may exhibit toxicity.
Infection thread initiation is thought to require localized degradation of the root hair wall at the site of infection, followed by new cell-wall synthesis (Gage 2004). It is tempting to speculate that, analogous to A. tumefaciens, the M. loti VirA is detecting the plant cell wall degradation and synthesis associated with infection thread initiation during the nodulation process and then activating VirG. The effector proteins transported by the T4SS then would act to suppress plant defense responses in compatible legumes such as Lotus corniculatus; whereas, in incompatible legumes such as Leucaena leucocephala, they are intercepted by the plant as avirulence proteins, leading to rapid induction of the defense responses. We are currently testing these hypotheses.

M. loti R7A contains two copies of the regulatory nodD gene on its symbiosis island, nodDl that is downstream of the nodulation gene nolL and nodD2 that is upstream of nolL and divergently transcribed from it (Sullivan et al. 2002). We isolated mutants in each of these genes and assayed their symbiotic phenotype on L. leucocephala. Both the wild-type and the nodD2 mutant formed small white nodules. These nodule structures were more defined than those previously observed (Hubber et al. 2004) and are similar to those formed by M. loti NZP2213 on L. leucocephala as reported by Pankhurst and associates (1987). These nodules do not contain infected plant cells; however, a few aborted infection threads containing rhizobia are present. The L. leucocephala seed used in this study was from a different source and variety than the seed used by Hubber and associates (2004), which likely explains the different wildtype nodulation responses. In contrast, the nodD1 mutant was completely $\mathrm{Nod}^{-}$on L. leucocephala. Thus, nodD1 is the important regulatory nod gene required for Nod factor synthesis in the interaction of $M$. loti with L. leucocephala. It, rather than nodD2, must also induce virA expression, because the nodD2 mutant showed a wild-type rather than vir phenotype on L. leucocephala. The fact that the wild-type and nodD2 mutant induced empty nodules strongly suggests that, although regulated by NodD1, the vir gene products act after Nod factor in the nodule developmental program.

In summary, this work establishes the involvement of NodD and VirA/VirG in regulation of the $M$. loti vir system. In the future, the involvement of secondary signals in optimizing vir gene expression in $M$. loti will be further investigated.

\section{MATERIALS AND METHODS}

\section{Bacterial strains and plasmids.}

The bacterial strains and plasmids used in this study are listed in Table 3.

\section{Media and growth conditions.}

E. coli strains were cultured at $37^{\circ} \mathrm{C}$ on Luria-Bertani agar or in 2YT broth (Sambrook et al. 1989). Strains of M. loti were grown at $28^{\circ} \mathrm{C}$ in TY (Beringer 1974) or Rhizobium-defined media with 4\% (wt/vol) glucose (Hubber et al. 2004). Media were supplemented with antibiotics as required at concentrations as described by Hubber and associates (2004).

DNA manipulations, bacterial crosses, and electroporations.

DNA manipulations, bacterial crosses, and electroporations were performed as described previously (Hubber et al. 2004).

\section{Construction of the $M$. loti R7A virGN54D mutant gene by site-directed mutagenesis.}

The mutation (a nucleotide substitution from A to $\mathrm{G}$ at position 160) that produces the VirGN54D protein was introduced into a cloned copy of $M$. loti virG using the Gene Editor in vitro Site-Directed Mutagenesis System (Promega). To create the 
template vector, a 2.7-kb PstI fragment containing the entire $\operatorname{vir} G$ gene and the preceding $1,045 \mathrm{bp}$ (nucleotides 62,892 to 64,854 of the symbiosis island) was cloned in the same orientation as the $\mathrm{Amp}^{\mathrm{r}}$ gene into pIC20R. Mutagenesis was carried out using the oligonucleotide virGSDMR (Table 4). The mutation was confirmed by sequencing, and a confirmed clone was cleaved with $\mathrm{XhoI}$ and $\mathrm{XbaI}$ to obtain the mutated virG fragment. This fragment was ligated into pFAJ1700 to create pAH4.

Creation of nodD mutants and transcriptional lac Z fusions. A pIJ3200 cosmid clone designated pSC7 containing a partial Sau3a restriction fragment spanning approximately $25 \mathrm{~kb}$ of the symbiosis island (approximate coordinates 130 to 155,000) was subjected to transposon mutagenesis using an in vitro transposon designated EZTn-GN. To construct EZTn-GN, a cassette containing the nptII gene and a promoterless gusA gene was subcloned from pCRS487 (Reeve et al. 1999) into the EZ::TN pMOD3<R6Kyori/MCS $>$ transposon construction vector (Epicentre) forming $\mathrm{pEZTn}-\mathrm{GN}$. The transposon, EZTn-GN, was amplified from $\mathrm{pEZTn}$-GN by polymerase chain reaction (PCR) using the $\mathrm{pMOD}<\mathrm{MCS}>$ forward and reverse primers (Epicentre), and then used to perform an in vitro transposition reaction on pSC7 using conditions recommended by the manufacturer. The mutagenized DNA was transformed into E. coli HB101 by

Table 3. Bacterial strains and plasmids used in this study

\begin{tabular}{|c|c|c|}
\hline Strain & Relevant characteristics & Reference, source \\
\hline \multicolumn{3}{|c|}{ Mesorhizobium loti } \\
\hline R7A & $\mathrm{Nod}^{+} \mathrm{Fix}^{-}$on Leucaena leucocephala & Sullivan et al. 2002 \\
\hline $\mathrm{NZP} 2213$ & Type strain; $\operatorname{Nod}^{+} \mathrm{Fix}^{-}$on L. leucocephala & Jarvis et al. 1982 \\
\hline NZP2037 & $\mathrm{Nod}^{+} \mathrm{Fix}^{+}$on L. leucocephala & Jarvis et al. 1982 \\
\hline AH46 & R7A virA:: lacZ, pFUS2 IDM, $\mathrm{Gm}^{\mathrm{r}}$ & Hubber et al. 2004 \\
\hline AH47 & R7A virG::lacZ, pFUS2 IDM, Gm ${ }^{\mathrm{r}}$ & Hubber et al. 2004 \\
\hline AH48 & R7A virB1::lacZ, pFUS2 IDM, $\mathrm{Gm}^{\mathrm{r}}$ & Hubber et al. 2004 \\
\hline AH49 & R7A virD4::lacZ, pFUS2 IDM, $\mathrm{Gm}^{\mathrm{r}}$ & Hubber et al. 2004 \\
\hline AH50 & R7A msi059::lacZ, pFUS2 IDM, Gm ${ }^{\mathrm{r}}$ & Hubber et al. 2004 \\
\hline AH51 & R7A msi061::lacZ, pFUS2 IDM, Gm ${ }^{\mathrm{r}}$ & Hubber et al. 2004 \\
\hline AH52 & R7A nifA $1:$ lacZ, pFUS2 IDM, Gm ${ }^{\mathrm{r}}$ & Hubber et al. 2004 \\
\hline AH55 & R7A $\Delta$ nod-box (5 virA gene) $: \Omega \Omega k a n, \mathrm{Nm}^{\mathrm{r}}$ & This work \\
\hline AH61 & R7A nolO::lacZ, pFUS2 IDM, $\mathrm{Gm}^{\mathrm{r}}$ & J. Sullivan, unpublished \\
\hline AH62 & R7A nodB::lacZ, pFUS2 IDM, Gm ${ }^{\mathrm{r}}$ & J. Sullivan, unpublished \\
\hline AH63 & AH55 containing virA::lacZ, $\mathrm{Nm}^{\mathrm{r}}, \mathrm{Gm}^{\mathrm{r}}$ & This work \\
\hline AH64 & AH55 containing virG $:$ lacZ, $\mathrm{Nm}^{\mathrm{r}}, \mathrm{Gm}^{\mathrm{r}}$ & This work \\
\hline AH65 & AH55 containing virB1::lacZ, $\mathrm{Nm}^{\mathrm{r}}, \mathrm{Gm}^{\mathrm{r}}$ & This work \\
\hline AH66 & AH55 containing virD4::lacZ, $\mathrm{Nm}^{\mathrm{r}}, \mathrm{Gm}^{\mathrm{r}}$ & This work \\
\hline $\mathrm{AH} 71$ & R7A msi061-CMD::lacZ, pFUS2 CMD, $\mathrm{Gm}^{\mathrm{r}}$ & This work \\
\hline AH90 & R7A $\Delta$ virA containing msi061-CMD::lacZ, $\mathrm{Gm}^{\mathrm{r}}$ & This work \\
\hline AH91 & R7A $\Delta v i r G$ containing msi061-CMD : lacZ, $\mathrm{Gm}^{\mathrm{r}}$ & This work \\
\hline AH92 & R7A nodD1::EZTn-GN, $\mathrm{Nm}^{\mathrm{r}}$ & This work \\
\hline AH93 & R7A $\operatorname{nodD} 2:: E Z T n-G N, \mathrm{Nm}^{\mathrm{r}}$ & This work \\
\hline \multicolumn{3}{|l|}{ Plasmids } \\
\hline pAH4 & pFAJ1700 containing the $M$. loti vir GN54D mutant gene and its promoter cloned as an EcoRI fragment, Tc ${ }^{\mathrm{r}}$ & This work \\
\hline pFAJ1700 & Broad-host-range vector, $\mathrm{Tc}^{\mathrm{r}}$ & Dombrecht et al. 2001 \\
\hline pFUS2 & oriV $V^{\mathrm{ColE} 1}$ oriT ${ }^{\mathrm{RK} 2}$ lacZ transcriptional reporter; suicide vector, $\mathrm{Gm}^{\mathrm{r}}$ & Antoine et al. 2000 \\
\hline $\mathrm{pHP} 45 \Omega-\mathrm{Km}$ & Contains $\Omega$ fragment; $\mathrm{Km}^{\mathrm{r}}$ & Fellay et al. 1987 \\
\hline pIC20R & $o r i V^{\mathrm{ColE} 1}, l a c Z \alpha, \mathrm{Ap}^{\mathrm{r}}$ & Marsh et al. 1984 \\
\hline pIJ3200 & Broad-host-range cosmid, $\mathrm{Tc}^{\mathrm{r}}$ & Liu et al. 1990 \\
\hline pJQ200SK & pACYC derivative, oriV ${ }^{\mathrm{p} 15 \mathrm{~A}}$ ori $\mathrm{T}^{\mathrm{RK} 2} \operatorname{sacB} ; \mathrm{Gm}^{\mathrm{r}}$ & Quandt and Hynes 1993 \\
\hline pMP2112 & pMP2733 containing the Rhizobium leguminosarum bv. trifolii nodD, $\mathrm{Sp}^{\mathrm{r}}$ & Lopez-Lara et al. 1995 \\
\hline pPH1J1 & IncP plasmid, $\mathrm{Gm}^{\mathrm{r}}$ & Hirsch and Beringer 1984 \\
\hline
\end{tabular}

${ }^{\mathrm{a}} \mathrm{Gm}^{\mathrm{r}}, \mathrm{Nm}^{\mathrm{r}}, \mathrm{Tc}^{\mathrm{r}}, \mathrm{Km}^{\mathrm{r}}, \mathrm{Ap}^{\mathrm{r}}$, and $\mathrm{Sp}^{\mathrm{r}}=$ gentamicin, neomycin, tetracycline, kanamycin, ampicillin, and spectinomycin resistant.

Table 4. Primers used in this study

\begin{tabular}{|c|c|c|c|}
\hline Name & Sequence $5^{\prime}$ to $3^{\prime a}$ & Used for $^{b}$ & Position $^{c}$ \\
\hline Gus-out & TTCGCGATCCAGACTGAATG & $\mathrm{S}$ & \\
\hline msi061CMDF & TTATTAGGATCCATCCATTGCTCGGCCTCC & CMD & $73,593-73,610$ \\
\hline msi061CMDR & ATAATTAAGCTTAGGTAGTCTCAGCAAGGT & CMD & $73,911-73,928$ \\
\hline$\Delta$ nod-boxdf & AAATTTAGATCTCTTCTTGAAAGCTAACCCTTG & ME & $49,727-49,747$ \\
\hline$\Delta$ nod-boxdr & TAATTTTCTAGATGCGTAGTTGATCTGAATCGT & $\mathrm{ME}$ & $50,777-50,797$ \\
\hline$\Delta$ nod-boxuf & TTTAAAACTAGTATTAGGCAGGCATTGGAGAAG & $\mathrm{ME}$ & $48,671-48,691$ \\
\hline$\Delta$ nod-boxur & ATAAATAGATCTCGGTTTTCGTTAGATGCGAGC & ME & $49,640-49,660$ \\
\hline virGSDMR & CCCGGCCTAGGTCGAGGTCAACAAC & SDM & $64,084-64,108$ \\
\hline$\Delta v i r G U F$ & AAATTTACTAGTCTGCATACTCAGGCATTGGTT & MD & $63,085-63,105$ \\
\hline$\Delta v i r G U R$ & ATAATTAGATCTTTGTCTAAAGCTGTTGCCGAG & MD & $63,890-63,910$ \\
\hline$\Delta v i r G D F$ & AAATTTAGATCTAGACGTTAGCTACGGAGGCA & MD & $64,629-64,648$ \\
\hline$\Delta v \operatorname{irGDR}$ & GAATTCCTCGAGCAGCAGCTGCAGCAGGCC & MD & $66,230-66,259$ \\
\hline$\triangle v i r A U F$ & TTTAAAACTAGTGCATTCTCGACCATCTCAAGAAGC & MD & $49,049-49,072$ \\
\hline$\triangle v i r A U R$ & AATAATGGATCCGCTCAAGCCATCACGCAC & MD & $50,146-50,163$ \\
\hline$\triangle v i r A D F$ & TTTAAAGGATCCCGAGACGTTGTTCTAGC & MD & $53,191-53,207$ \\
\hline$\triangle v i r A D R$ & TTTAAACTCGAGTATAACGATCTGGAGGACATC & MD & $54,073-54,093$ \\
\hline
\end{tabular}

${ }^{a}$ Restriction sites incorporated into primers are underlined.

b $\mathrm{S}=$ sequencing, $\mathrm{CMD}=$ cis-merodiploid pFUS2 fusion, $\mathrm{ME}=$ marker exchange, $\mathrm{SDM}=$ site-directed mutagenesis, and $\mathrm{MD}=$ markerless deletion.

${ }^{c}$ Symbiosis island coordinates, numbered according to annotated R7A symbiosis island sequence (Sullivan et al. 2002). 
electroporation and kanamycin- and tetracycline-resistant transformants were selected. The positions of EZTn-GN insertions were mapped by restriction endonuclease analysis and by cloning EcoRI fragments containing the insertions into pBluescript SKII and sequencing these clones using the primer Gus-out (Table 4). pSC7 clones containing transposon insertions which mapped to the nod D1 and nod $\mathrm{D} 2$ genes were transferred to R7A by electroporation, and marker exchange of the transposon insertions was forced by plasmid incompatibility using pPH1JI (Ruvkun and Ausubel 1981). pPH1JI was cured from strains by mating in pLAFR 1 and selecting for gentamicin- and tetracycline-resistant colonies. The resulting mutants, designated AH92 (nodD1::EZTn-GN) and AH93 (nodD2:: EZTn-GN), were confirmed by Southern hybridization.

Replacement of the nod-box region upstream of virA with the $\Omega$ kan interposon (Fellay et al. 1987) was achieved using marker exchange (Ruvkun and Ausubel 1981). Regions flanking the nod box were obtained by PCR using oligonucleotide primer pairs

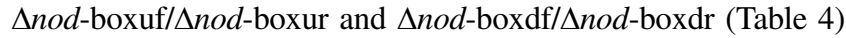
containing restriction endonuclease sites (SpeI and BglII for the upstream flanking region and $B g l I I$ and $X b a \mathrm{I}$ for the downstream flanking region). The gene replacement cassette containing the $\Omega$ kan cassette inserted between the two PCR products was constructed in pIJ3200 and the resulting plasmid was used to achieve marker exchange as described above to produce mutant strain AH55, which was confirmed by PCR analysis.

To construct the CMD fusion strain AH71, oligonucleotide primer pairs msi061CMDF and msi061CMDR (Table 4) were designed to amplify a 331-bp region containing the putative promoter and $5^{\prime}$ region of msi061. The PCR product was cloned into the suicide vector pFUS2 (Antoine et al. 2000) adjacent to its promoterless $l a c Z$ gene and the clone confirmed by DNA sequencing. Double nodD/IDMs and double nodbox:: $\Omega$ kan/IDM mutants were constructed using the pFUS2 clones that were used to construct the single vir mutants (Hubber et al. 2004). The pFUS2 clones were transferred from E. coli $\mathrm{S} 17-1$ into the M. loti strains by conjugation. Transconjugants were passaged four times on selective media, and the strains were confirmed by Southern hybridization analysis.

Markerless deletions of the virA and virG genes were constructed in $M$. loti R7A using the suicide vector pJQ200SK (Quandt and Hynes 1993). Oligonucleotide primer pairs which contained restriction endonuclease sites to facilitate cloning (Table 4) were designed to amplify 1 - to $2-\mathrm{kb}$ regions that flanked the regulatory vir genes. The primer pairs used were $\Delta$ virGUF/ $\Delta$ virGUR and $\Delta$ virGDF/ $\Delta$ virGDR for $\operatorname{vir} G$ and $\Delta$ virAUF/ $\Delta$ virAUR and $\Delta$ virADF/ $\Delta$ virADR for $v i r A$. The PCR products were digested with appropriate enzymes and ligated into pJQ200SK digested with SpeI and XhoI. Clones containing both PCR products were confirmed by sequencing and then transferred to R7A, followed by selection for Gent ${ }^{\mathrm{r}}$ isolates. Integration at the correct site was confirmed by Southern hybridization. A second homologous recombination event that excised the vector was detected by loss of sucrose sensitivity, due to the loss of the $s a c B$ gene present on pJQ200SK. Strains with the desired deletion were confirmed by PCR analysis and Southern hybridization.

\section{Analysis of vir gene expression.}

$\beta$-Galactosidase assays were performed on $M$. loti G/RDM broth ( $\mathrm{pH}$ 6.0) cultures in midexponential or stationary phase as described previously (Miller 1972). Naringenin $(1 \mu \mathrm{M})$ was added to broths where required.

\section{Nodulation tests.}

L. leucocephala var. Cunningham was grown under controlled environmental conditions of $70 \%$ humidity, 22 to $25^{\circ} \mathrm{C}$ during the day, and $14^{\circ} \mathrm{C}$ at night on a cycle of 16 and $8 \mathrm{~h}$ of day and night, respectively. Seed were placed in a small amount of concentrated sulfuric acid for 5 to $10 \mathrm{~min}$. After removing the acid, the seed were washed, incubated overnight in fresh sterile distilled water, washed twice, and transferred to watery agar $(0.8 \%)$ for 2 days in the dark to germinate. Seedlings were grown, inoculated, and analyzed as described previously (Hubber et al. 2004).

\section{ACKNOWLEDGMENTS}

This work was supported by a grant from the Marsden Fund administered by the Royal Society of New Zealand.

\section{LITERATURE CITED}

Antoine, R., Alonso, S., Raze, D., Coutte, L., Lesjean, S., Willery, E., Locht, C., and Jacob-Dubuisson, F. 2000. New virulence-activated and virulence-repressed genes identified by systematic gene inactivation and generation of transcriptional fusions in Bordetella pertussis. J. Bacteriol. 182:5902-5905.

Ausmees, N., Kobayashi, H., Deakin, W. J., Marie, C., Krishnan, H. B., Broughton, W. J., and Perret, X. 2004. Characterization of NopP, a type III secreted effector of Rhizobium sp. strain NGR234. J. Bacteriol. 186:4774-4780.

Bartsev, A. V., Boukli, N. M., Deakin, W. J., Staehelin, C., and Broughton, W. J. 2003. Purification and phosphorylation of the effector protein NopL from Rhizobium sp. NGR234. FEBS (Fed. Eur. Biochem. Soc.) Lett. 554:271-274.

Bartsev, A. V., Deakin, W. J., Boukli, N. M., McAlvin, C. B., Stacey, G., Malnoe, P., Broughton, W. J., and Staehelin, C. 2004. NopL, an effector protein of Rhizobium sp. NGR234, thwarts activation of plant defense reactions. Plant Physiol. 134:871-879.

Becker, A., Fraysse, N., and Sharypova, L. 2005. Recent advances in studies on structure and symbiosis-related function of rhizobial K-antigens and lipopolysaccharides. Mol. Plant-Microbe Interact. 18:899-905.

Beringer, J. E. 1974. R factor transfer in Rhizobium leguminosarum. J. Gen. Microbiol. 84:188-198.

Brencic, A., and Winans, S. C. 2005. Detection of and response to signals involved in host-microbe interactions by plant-associated bacteria. Microbiol. Mol. Biol. Rev. 69:155-94.

Christie, P. J., Atmakuri, K., Krishnamoorthy, V., Jakubowski, S., and Cascales, E. 2005. Biogenesis, architecture, and function of bacterial type IV secretion systems. Annu. Rev. Microbiol. 59:451-485.

Das, A., Stachel, S.E., Ebert, P.R., Allenza, P., Montoya, H., and Nester, E. 1986. Promoters of Agrobacterium tumefaciens Ti plasmid virulence genes. Nucleic Acids Res. 14:1355-1364.

Delgado, J., Forst, S., Harlocker, S., and Inouye, M. 1993. Identification of a phosphorylation site and functional analysis of conserved asparticacid residues of OmpR, a transcriptional activator for $\mathrm{OmpF}$ and $\mathrm{OmpC}$ in Escherichia coli. Mol. Microbiol. 10:1037-1047.

Dombrecht, B., Vanderleyden, J., and Michiels, J. 2001. Stable RK2-derived cloning vectors for the analysis of gene expression and gene function in gram-negative bacteria. Mol. Plant-Microbe Interact. 14:426-430.

Fellay, R., Frey, J., and Krisch, H. 1987. Interposon mutagenesis of soil and water bacteria - a family of DNA fragments designed for in vitro insertional mutagenesis of gram-negative bacteria. Gene 52:147-154.

Fisher, R. F., and Long, S. R. 1993. Interactions of NodD at the nod box: NodD binds to two distinct sites on the same face of the helix and induces a bend in the DNA. J. Mol. Biol. 233:336-348.

Fraysse, N., Couderc, F., and Poinsot, V. 2003. Surface polysaccharide involvement in establishing the rhizobium-legume symbiosis. Eur. J. Biochem. 270:1365-1380

Gage, D. J. 2004. Infection and invasion of roots by symbiotic, nitrogenfixing rhizobia during nodulation of temperate legumes. Microbiol. Mol. Biol. Rev. 68:280-300.

Gao, R., Mukhopadhyay, A., Fang, F., and Lynn, D. G. 2006. Constitutive activation of two-component response regulators: Characterization of VirG activation in Agrobacterium tumefaciens. J. Bacteriol. 188:5204-5211.

Geurts, R., Fedorova, E., and Bisseling, T. 2005. Nod factor signaling genes and their function in the early stages of Rhizobium infection. Curr. Opin. Plant Biol. 8:346-352.

Han, D. C., Chen, C. Y., Chen, Y. F., and Winans, S. C. 1992. Altered-function mutations of the transcriptional regulatory gene virG of Agrobacterium tumefaciens. J. Bacteriol. 174:7040-7043.

Hirsch, P. R., and Beringer, J. E. 1984. A physical map of pPH1JI and pJB4JI. Plasmid 12:139-141. 
Huang, Y., Morel, P., Powell, B., and Kado, C. I. 1990. VirA a coregulator of Ti-specified virulence genes, is phosphorylated in vitro. J. Bacteriol. 171:1142-1144.

Hubber, A., Vergunst, A. C., Sullivan, J. T., Hooykaas, P. J. J., and Ronson, C. W. 2004. Symbiotic phenotypes and translocated effector proteins of the Mesorhizobium loti strain R7A VirB/D4 type IV secretion system. Mol. Microbiol. 54:561-574.

Jarvis, B. D. W., Pankhurst, C. E., and Patel, J. J. 1982. Rhizobium loti, a new species of legume root nodule bacteria. Int. J. Syst. Bacteriol. 32:378-380.

Jin, S. G., Prusti, R. K., Roitsch, T., Ankenbauer, R. G., and Nester, E. W. 1990a. Phosphorylation of the VirG protein of Agrobacterium tumefaciens by the autophosphorylated VirA protein: Essential role in the biological activity of VirG. J. Bacteriol. 172:4945-4950.

Jin, S. G., Roitsch, T., Ankenbauer, R. G., Gordon, M. P., and Nester, E. W. 1990b. The VirA protein of Agrobacterium tumefaciens is autophosphorylated and is essential for vir gene regulation. J. Bacteriol. 172:525-530.

Jin, S. G., Roitsch, T., Christie, P. J., and Nester, E. W. 1990c. The regulatory VirG protein specifically binds to a cis-acting regulatory sequence involved in transcriptional activation of Agrobacterium tumefaciens virulence genes. J. Bacteriol. 172:531-537.

Jin, S. G., Song, Y. N., Pan, S. Q., and Nester, E. W. 1993. Characterization of a VirG mutation that confers constitutive virulence gene expression in Agrobacterium. Mol. Microbiol. 7:555-562.

Klose, K. E., Weiss, D. S., and Kustu, S. 1993. Glutamate at the site of phosphorylation of nitrogen-regulatory protein NtrC mimics aspartylphosphate and activates the protein. J. Mol. Biol. 232:67-78.

Kobayashi, H., Naciri-Graven, Y., Broughton, W. J., and Perret, X. 2004. Flavonoids induce temporal shifts in gene-expression of nod-box controlled loci in Rhizobium sp. NGR234. Mol. Microbiol. 51:335-347.

Krause, A., Doerfel, A., and Gottfert, M. 2002. Mutational and transcriptional analysis of the type III secretion system of Bradyrhizobium japonicum. Mol. Plant-Microbe Interact. 15:1228-1235.

Krishnan, H. B., Lorio, J., Kim, W. S., Jiang, G. Q., Kim, K. Y., DeBoer, M., and Pueppke, S. G. 2003. Extracellular proteins involved in soybean cultivar-specific nodulation are associated with pilus-like surface appendages and exported by a type III protein secretion system in Sinorhizobium fredii USDA257. Mol. Plant-Microbe Interact. 16:617-625.

Lan, C. Y., and Igo, M. M. 1998. Differential expression of the OmpF and OmpC porin proteins in Escherichia coli $\mathrm{K}-12$ depends upon the level of active OmpR. J. Bacteriol. 180:171-174.

Leroux, B., Yanofsky, M. F., Winans, S. C., Ward, J. E., Ziegler, S. F., and Nester, E. W. 1987. Characterisation of the virA locus of Agrobacterium tumefaciens: A transcriptional regulator and host range determinant. EMBO (Eur. Mol. Biol. Organ.) J. 6:849-856

Limpens, E., Franken, C., Smit, P., Willemse, J., Bisseling, T., and Geurts, R. 2003. LysM domain receptor kinases regulating rhizobial Nod factor-induced infection. Science 302:630-633.

Liu, Y. N., Tang, J. L., Clarke, B. R., Dow, J. M., and Daniels, M. J. 1990. A multipurpose broad host range cloning vector and its use to characterize an extracellular protease gene of Xanthomonas campestris pathovar campestris. Mol. Gen. Genet. 220:433-440.

Long, S. R. 1996. Rhizobium symbiosis: Nod factors in perspective. Plant Cell 8:1885-1898.

Lopez-Lara, I. M., Vandenberg, J. D. J., Thomas-Oates, J. E., Glushka, J., Lugtenberg, B. J. J., and Spaink, H. P. 1995. Structural identification of the lipo-chitin oligosaccharide nodulation signals of Rhizobium loti. Mol. Microbiol. 15:627-638

Lorio, J. C., Kim, W. S., and Krishnan, H. B. 2004. NopB, a soybean cultivar-specificity protein from Sinorhizobium fredii USDA257, is a type III secreted protein. Mol. Plant-Microbe Interact. 17:1259-1268.

Madsen, E. B., Madsen, L. H., Radutoiu, S., Olbryt, M., Rakwalska, M., Szczyglowski, K., Sato, S., Kaneko, T., Tabata, S., and Sandal, N. 2003. A receptor kinase gene of the LysM type is involved in legume perception of rhizobial signals. Nature 425:637-640.

Marie, C., Broughton, W. J., and Deakin, W. J. 2001. Rhizobium type III secretion systems: Legume charmers or alarmers? Curr. Opin. Plant Biol. 4:336-342.

Marie, C., Deakin, W. J., Viprey, V., Kopcinska, J., Golinowski, W., Krishnan, H. B., Perret, X., and Broughton, W. J. 2003. Characterization of Nops, nodulation outer proteins, secreted via the type III secretion system of NGR234. Mol. Plant-Microbe Interact. 16:743-751.

Marie, C., Deakin, W. J., Ojanen-Reuhs, T., Diallo, E., Reuhs, B., Broughton, W. J., and Perret, X. 2004. TtsI, a key regulator of Rhizobium species NGR234 is required for type III-dependent protein secretion and synthesis of rhamnose-rich polysaccharides. Mol. PlantMicrobe Interact. 17:958-966.

Marsh, J. L., Erfle, M., and Wykes, E. J. 1984. The pIC plasmid and phage vectors with versatile cloning sites for recombinant selection by insertional inactivation. Gene 32:481-485.

Miller, J. H. 1972. Experiments in Molecular Genetics. Cold Spring Har- bor Laboratory Press, Cold Spring Harbor, NY, U.S.A.

Niwa, S., Kawaguchi, M., Imaizumi-Anraku, H., Chechetka, S. A., Ishizaka, M., Ikuta, A., and Kouchi, H. 2001. Responses of a model legume Lotus japonicus to lipochitin oligosaccharide nodulation factors purified from Mesorhizobium loti JRL501. Mol. Plant-Microbe Interact. 14:848-856.

Noel, K. D., and Duelli, D. M. 2000. Rhizobium lipopolysaccharide and its role in symbiosis. Pages 415-431 in: Prokaryotic Nitrogen Fixation: A Model System for Analysis of Biological Processes. E. W. Triplett, ed. Horizon Scientific Press, Wymondham, U.K.

Pankhurst, C. E., Hopcroft, D. H., and Jones, W. T. 1987. Comparative morphology and flavolan content of Rhizobium loti induced effective and ineffective root nodules on Lotus species, Leucaena leucocephala, Carmichaelia flagelliformis, Ornithopus sativus, and Clianthus puniceus. Can. J. Bot. 65:2676-2685.

Pazour, G. J., and Das, A. 1990. Characterization of the VirG binding-site of Agrobacterium tumefaciens. Nucleic Acids Res. 18:6909-6913.

Pazour, G. J., Ta, C. N., and Das, A. 1992. Constitutive mutations of Agrobacterium tumefaciens transcriptional activator VirG. J. Bacteriol. 174:4169-4174.

Peck, M. C., Fisher, R. F., and Long, S. R. 2006. Diverse flavonoids stimulate NodD1 binding to nod gene promoters in Sinorhizobium meliloti. J. Bacteriol. 188:5417-5427.

Perret, X., Staehelin, C., and Broughton, W. J. 2000. Molecular basis of symbiotic promiscuity. Microbiol. Mol. Biol. Rev. 64:180-201.

Powell, B. S., Rogowsky, P. M., and Kado, C. I. 1989. virG of Agrobacterium tumefaciens plasmid pTiC58 encodes a DNA-binding protein Mol. Microbiol. 3:411-419.

Price, N. P. J. 1999. Carbohydrate determinants of Rhizobium-legume symbioses. Carbohydr. Res. 317:1-9.

Quandt, J., and Hynes, M. F. 1993. Versatile suicide vectors which allow direct selection for gene replacement in gram-negative bacteria. Gene 127:15-21.

Radutoiu, S., Madsen, L. H., Madsen, E. B., Felle, H. H., Umehara, Y. Gronlund, M., Sato, S., Nakamura, Y., Tabata, S., Sandal, N., and Stougaard, J. 2003. Plant recognition of symbiotic bacteria requires two LysM receptor-like kinases. Nature 425:585-592.

Reeve, W. G., Tiwari, R. P., Worsley, P. S., Dilworth, M. J., Glenn, A. R., and Howieson, J. G. 1999. Constructs for insertional mutagenesis, transcriptional signal localization and gene regulation studies in root nodule and other bacteria. Microbiology 145:1307-1316.

Rostas, K., Kondorosi, E., Horvath, B., Simonesits, A., and Kondorosi, A. 1986. Conservation of extended promoter regions of nodulation genes in Rhizobium. Proc. Natl. Acad. Sci. U.S.A. 83:1757-1761.

Ruvkun, G. B., and Ausubel, F. M. 1981. A general method for site-directed mutagenesis in prokaryotes. Nature 289:85-88.

Sambrook, J., Fritsch, E. F., and Maniatis, T. 1989. Molecular Cloning, A Laboratory Manual, 2nd ed. Cold Spring Harbor Laboratory Press, Cold Spring Harbor, NY, U.S.A.

Scheeren-Groot, E. P., Rodenburg, K. W., den Dulk-Ras, A., Turk, S. C., and Hooykaas, P. J. J. 1994. Mutational analysis of the transcriptional activator VirG of Agrobacterium tumefaciens. J. Bacteriol. 176:6418-6426.

Schlaman, H. R. M., Phillips, D. A., and Kondorosi, A. 1998. Genetic organisation and transcriptional regulation of rhizobial nodulation genes. Pages 361-386 in: The Rhizobiaceae. H. P. Spaink, A. Kondorosi, and P. J. J. Hooykaas, eds. Kluwer Academic Publishers, Dordrecht, The Netherlands.

Skorpil, P., Saad, M. M., Boukli, N. M., Kobayashi, H., Ares-Orpel, F. Broughton, W. J., and Deakin, W. J. 2005. NopP, a phosphorylated effector of Rhizobium sp. strain NGR234, is a major determinant of nodulation of the tropical legumes Flemingia congesta and Tephrosia vogelii. Mol. Microbiol. 57:1304-1317.

Spaink, H. P. 2000. Root nodulation and infection factors produced by rhizobial bacteria. Annu. Rev. Microbiol. 54:257-288.

Sullivan, J. T., Trzebiatowski, J. R., Cruickshank, R. W., Gouzy, J., Brown, S. D., Elliot, R. M., Fleetwood, D. J., McCallum, N. G., Rossbach, U., Stuart, G. S., Weaver, J. E., Webby, R. J., de Bruijn, F. J., and Ronson, C. W. 2002. Comparative sequence analysis of the symbiosis island of Mesorhizobium loti strain R7A. J. Bacteriol. 184:3086-3095.

van Rhijn, P., and Vanderleyden, J. 1995. The Rhizobium-plant symbiosis Microbiol. Rev. 59:124-142.

Viprey, V., Del Greco, A., Golinowski, W., Broughton, W. J., and Perret, X. 1998. Symbiotic implications of type III protein secretion machinery in Rhizobium. Mol. Microbiol. 28:1381-1389.

Winans, S. C., Ebert, P. R., Stachel, S. E., Gordon, M. P., and Nester, E. W. 1986. A gene essential for Agrobacterium virulence is homologous to a family of positive regulatory loci. Proc. Natl. Acad. Sci. U.S.A. 83:8278-8282.

Zhu, J., Oger, P. M., Schrammeijer, B., Hooykaas, P. J. J., Farrand, S. K., and Winans, S. C. 2000. The bases of crown gall tumorigenesis. J. Bacteriol. 182:3885-3895. 